\title{
Rethinking Dropout in Online Higher Education: The Case of the Universitat Oberta de Catalunya
}
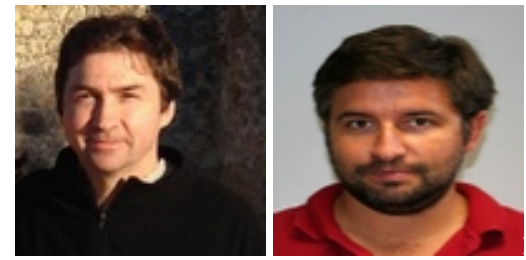

Josep Grau-Valldosera and Julià Minguillón

Universitat Oberta de Catalunya, Spain

\section{Abstract}

In recent years, several studies have been carried out into the reasons why students drop out of online higher education, following the rise in the relative weight of this form of education. However, more effort has gone into analyzing the causes of this phenomenon than into trying to characterize students who drop out, that is defining what a dropout student is. But obtaining a proper definition of dropout is just as important as describing its causes. It also appears that the definition of dropout is very sensitive to context. As one of the main findings of this article, we reach a pure empirical definition, at a programme level, of students who drop out of an online higher education context with non-mandatory enrollment. This definition is based on the probability of students not continuing a specific academic programme following several consecutive semesters of "theoretical break", and is highly adaptable to institutions offering distance education with no permanence requirements, that is ones offering the possibility of taking breaks. Our findings show that there are differences regarding the number of consecutive semesters that define dropout depending on whether the programme requires previous experience or not. Additionally, we observe significant differences in the dropout rate between specific programmes, as well as a higher level of dropout in the first semesters. Analyzing the reasons behind these facts should help higher education institutions to make more sound and efficient decisions.

Keywords: Dropout; early dropout; higher education; online university; distance education; learning analytics 


\section{Introduction}

University dropout is a major issue and should be seen as a failure of the higher education system to create an outcome (graduates) after having invested a significant amount of resources, normally publicly funded (OECD, 2012). However, the financial costs of dropout are only part of the total costs: Non-pecuniary (or affective) costs more difficult to measure - are also important for dropout students (J ohnes, 1990).

It should be noted that university dropout is a multidimensional phenomenon that needs to be correctly defined before any thorough analysis of its causes can be carried out. One of the authors who has put great emphasis on creating a university dropout doctrine is Vincent Tinto (1975). Tinto stresses the importance of reaching a good definition of university dropout, which he sees as essential as detecting the causes of this dropout (emphasis added by authors):

Despite the very extensive literature on dropout from higher education, much remains unknown about the nature of the dropout process. In large measure, the failure of past research to delineate more clearly the multiple characteristics of dropout can be traced to two major shortcomings: namely, inadequate attention given to questions of definition and to the development of theoretical models that seek to explain, not simply to describe, the processes that bring individuals to leave institutions of higher education. (p. 89)

In a more recent vision, Lee and Choi (2011) have reviewed research on online course dropout. The results of this analysis reveal that so far research has focused mainly on analysing the causes of dropout on a course level. As stated by the authors, there is a need for a definition of dropout: "Future studies, grounded in a clear, standard definition of the term 'dropout', should be conducted in order to investigate dropout factors which prevail across different online courses" (p. 603).

Nowadays, high levels of university dropout are a concern for most governments with developed university systems. For example, in Spain, the Conferencia de Rectores de las Universidades Españolas (CRUE Conference of Spanish University Vice-Chancellors) has established an arbitrary definition of the dropout rate as the percentage of students who have not enrolled for either the academic year when they should theoretically finish their course or for the following academic year, with respect to the total number of students who enrolled on this course in the initial semester. This definition applies to both brick-and-mortar and online universities (CRUE, 2008). Although the CRUE definition might be valid for brick-and-mortar universities, where students value their courses as their main priority over other professional or family duties, it does not seem to be as valid for online or open universities, where the majority of students have bigger 
work and family commitments, and where, therefore, they are more likely to take breaks (semesters without enrollment). ${ }^{1}$ The main challenge lies in the fact that even if a given student fails to enroll for several successive semesters, it is impossible to be $100 \%$ sure that this student has definitively dropped out of their programme, as they may simply be taking a longer break. We can therefore conclude that the official definition of dropout in Spain does not reflect the specific characteristics of online higher education.

According to the aforementioned official definition of dropout rate for the Spanish university system, it can be seen that the Universitat Oberta de Catalunya (UOC) has a higher dropout rate than brick-and-mortar universities: $39 \%$ and $26 \%$, respectively (CRUE, 2008). However, throughout the rest of this paper, the official definition of dropout will be questioned. As mentioned, the very nature of the UOC - and the majority of institutions that provide adult distance education - justifies the effort of finding a tailored definition of dropout.

Therefore, the main aim of this paper is to define dropout in online higher education at programme level, following an empirical process based on an in-depth analysis of enrollment data. The definition reached using this methodology, although bearing in mind the special characteristics of UOC, should be suitable to other open/online institutions that offer courses of a certain length with non-mandatory enrollment and no (or indulgent) permanence requirements. Anyway, differences between institutions have to be considered. For example, concerning the "time limit to graduation" (which does not exist at UOC), the Open University (UK) establishes a maximum time limit for all undergraduate qualifications to be passed, while in Athabasca University (Canada) some programmes allow a maximum term to complete the degree requirements; furthermore, students should remain active in the programme or they are required to re-enroll and pay a reactivation fee. Other important aspects would be the meaning of "open". For example, OU UK and Athabasca do not have admission requirements, which is not the case of UOC, or the possibility of enrolling in flexible dates (which is possible in Athabasca).

The rationale of this research is that the official dropout definition does not capture the true nature of dropouts in online (or distance/open) institutions, so no comparison between higher education institutions can be done. Furthermore, the definition of dropout given in this paper can be tailored to each degree, as it captures the differences in the enrollment and break sequences of the students for each one of the programmes analyzed. Being closer to reality, this definition also allows us to know when dropout really happens, usually before the official definition does. This early detection enables institutions to promptly react to potential dropouts.

To obtain a specific dropout definition, we undertake an empirical quantitative analysis on the basis of a statistical representation. We should stress that this definition of

\footnotetext{
${ }^{1}$ In the case of the UOC, a $100 \%$ online university, most students study for twice the theoretical course length. The university's enrolment regulations permit this and also allow students to take a break between two academic semesters.
} 
dropout will be established from an institutional perspective, that is without considering students' perspective; in this way of thinking, students may drop out from the point of view of the university, but they may be fully satisfied with the teaching experience, having achieved their personal learning objectives, and may not consider themselves to be a dropout case. Therefore, from an institutional point of view, the definition of dropout will always be harsher than reality.

\section{Existing Definitions of University Dropout}

The difficulty of defining dropout was already acknowledged in traditional face-to-face education. Tinto (1982) dedicates an entire article to this objective, stressing the different possible definitions of dropout depending on the individual or institutional perspective, and Astin (1971) says that it is impossible to find a perfect classification of dropouts versus non-dropouts any time while students are still alive, as there is always the possibility that they may return to college. Only a good approximation would be possible:

(...) the term 'dropout' is imperfectly defined: the socalled dropouts may ultimately become non-dropouts and vice versa... But there seems to be no practical way out of the dilemma: A "perfect" classification of dropouts versus non-dropouts could only be achieved when all the students had either died without ever finishing college or had finished college. (p. 15)

Therefore, dropout (both as an "institutional problem" and as a "definition challenge") has been inherited by distance education from its traditional face-to-face counterpart. As an "institutional problem", recent studies indicate that online courses have significantly higher student dropout rates than conventional courses (Tello, 2007); as a "definition challenge", the special characteristics of students, with greater work and family time constraints, make the dropout decision more complex than simply an "academic" one. The summary of online dropout studies given in Lee and Choi (2011) shows the heterogeneous nature of definitions of dropout (see Table 1): as a formal process not always asked for (Finnegan et al., 2009), as simply "not starting" the course (Kemp, 2002), as a voluntary withdrawal entailing financial penalties (Levy, 2007), and so on. 
Table 1

Heterogeneity of Dropout Definitions (Extracted from Lee \&Choi, 2011)

\begin{tabular}{|c|c|c|}
\hline Author & Year & Dropout definition \\
\hline Castles & 2004 & $\begin{array}{l}\text { Dropout: students who had formally withdrawn, had left } \\
\text { without notifying the university, or did not complete a course } \\
\text { during a semester }\end{array}$ \\
\hline $\begin{array}{l}\text { Cheung and } \\
\text { Kan }\end{array}$ & 2002 & Dropout: students who were awarded fail or resit \\
\hline Dupin-Bryant & 2004 & $\begin{array}{l}\text { Dropout: student who did not complete a course during a } \\
\text { semester }\end{array}$ \\
\hline $\begin{array}{l}\text { Fennegan et } \\
\text { al. }\end{array}$ & 2009 & $\begin{array}{l}\text { Withdrawal: (1) withdrawers-had to withdraw from the } \\
\text { course officially; (2) successful completers-completed the } \\
\text { course receiving a grad of A, B, or C; (3) non-successful } \\
\text { completers-received a grade of D or F or an incomplete }\end{array}$ \\
\hline Frydenberg & 2007 & $\begin{array}{l}\text { Dropout: students who registered but dropped prior to class } \\
\text { start, prior to start of instruction, during the orientation } \\
\text { week, or after the orientation week }\end{array}$ \\
\hline $\begin{array}{l}\text { Ivankova and } \\
\text { Stick }\end{array}$ & 2007 & $\begin{array}{l}\text { Dropout: students who withdrew or were terminated from the } \\
\text { program }\end{array}$ \\
\hline Kemp & 2002 & $\begin{array}{l}\text { Non-completion: students who did not commence work on } \\
\text { their course, withdrew from their course, or received an } \\
\text { academic failing grade }\end{array}$ \\
\hline Levy & 2007 & $\begin{array}{l}\text { Dropout-students are those who voluntarily withdraw from e- } \\
\text { learning while acquiring financial penalties }\end{array}$ \\
\hline Moore et al. & 2003 & $\begin{array}{l}\text { Non-completion: students who received a grade of F or } \\
\text { officially withdrew from the course }\end{array}$ \\
\hline $\begin{array}{l}\text { Morgan and } \\
\text { Tam }\end{array}$ & 1999 & $\begin{array}{l}\text { Non-completion: students who did not enroll in the following } \\
\text { semester }\end{array}$ \\
\hline Morris et al. & 2005 & $\begin{array}{l}\text { Withdrawal: students who completed the official withdrawal } \\
\text { process. Non-successful completers: students who received a } \\
\text { grad of D, F, or an incomplete }\end{array}$ \\
\hline Perry & 2008 & $\begin{array}{l}\text { Withdrawal: centre withdrawal (student unable to fulfill the } \\
\text { program requirement to complete two courses per year), } \\
\text { academic withdrawal (students who fail two courses in the } \\
\text { program), and student withdrawal (students who leave for } \\
\text { reasons not obviously related to centre or academic } \\
\text { requirements) }\end{array}$ \\
\hline $\begin{array}{l}\text { Pierrakeas et } \\
\text { al. }\end{array}$ & 2004 & $\begin{array}{l}\text { Dropout: including those students who enrolled in at least } \\
\text { one module, but failed to deliver one project; who did not } \\
\text { complete some or all of their assignment, but indicated they } \\
\text { would continue their studies; who would not re-enroll at a } \\
\text { future date; who enrolled in multiple courses, who had } \\
\text { successfully completed some but not all of their assignments, } \\
\text { and had indicated they would not re-enroll at a future date }\end{array}$ \\
\hline $\begin{array}{l}\text { Pigliapoco and } \\
\text { Bogliolo }\end{array}$ & $\ldots$ & $\begin{array}{l}\text { Dropout: students who did not renew the enrollment at the } \\
\text { end of the first year }\end{array}$ \\
\hline Shin and Kim & 1999 & $\begin{array}{l}\text { Dropout: students who fail to register after three consecutive } \\
\text { terms of non-enrollment }\end{array}$ \\
\hline Tello & 2007 & $\begin{array}{l}\text { Non-persistence: students who filed paperwork with the } \\
\text { Registrar's office declaringwithdrawal from a course prior to } \\
\text { the final grading period }\end{array}$ \\
\hline $\begin{array}{l}\text { Willging and } \\
\text { J ohnson }\end{array}$ & 2004 & $\begin{array}{l}\text { Dropout: students who dropped out of the degree program } \\
\text { after starting their first course }\end{array}$ \\
\hline
\end{tabular}


Lee and Choi (2011) point out that

Many of the studies (13 studies, 37\%) we examined provided no clear definition of dropout from online courses. Furthermore, although some studies did explicitly define the term "student dropout," their definitions were not consistent with one another, which made it difficult for us to compare dropout factors and retention strategies across universities. (p. 596)

The dropout definition given in this paper sets the basis of a potentially standardizable dropout definition due to the fact that it is based on the objective analysis of students' enrollment behaviour, far from administrative or even academic arbitrarity. Therefore, this definition would, on one hand, serve the objective of giving a more precise image of the dropout problem at UOC and, on the other hand, set up a measure that is adaptable to other institutions that have similar enrollment requirements to UOC. Additionally, it should be stressed that the analysis considers data for the entire student population, not just a sample, which, attending to Lee and Choi (2011), makes it possible to generalise the results.

The rest of this paper is organised as follows: The next section describes the methodology and data used to reach a definition of dropout. This definition is based on analysis of the enrollment behaviour of students on the programmes considered throughout the course of their academic life. The Results section explores the outcomes given in the previous section in greater depth. First, we analyse the differences between programmes with regard to the minimum number of consecutive break semesters required to consider this a case of dropout. Then, this value is used as a parameter to calculate the levels of final and first semester dropout. Finally, the last section summarizes the conclusions and future research in this subject.

\section{Data and Methodology}

Since its inception in 1994 as a purely online university, the Universitat Oberta de Catalunya (UOC) has been able to position itself among the main universities of the Catalan and Spanish university systems. Most of the students at the UOC (currently more than 60,000) are adults who have a profile that hardly could fit into the traditional university system, thus finding in the UOC an opportunity to start or continue their higher education grades, in a very innovative environment (Sangrà, 2002). The intensive use of ICT for both the teaching/learning processes and management allow researchers and practitioners to obtain data about what happens in the UOC Virtual Campus, which is continuously being improved according to such findings. This study is the result of trying to answer a very simple question: "What is the real dropout rate for students taking the <whatever> degree?", putting the emphasis on "real." In order to do 
so, we decided to analyze the enrollment patterns of all available data at UOC, to see whether there is a simple way to establish a criterion to differentiate breaks from true dropouts.

The data used in this paper are gathered from UOC academic databases. Data have been validated according to UOC internal privacy policies. For this initial study, only student enrollments are analysed. During a period of 26 semesters, UOC received 62,450 new students enrolled on officially recognised degrees in Catalan; $13.3 \%$ of them finished a degree, whilst $57.6 \%$ dropped out of their studies. These figures only include students who have been enrolled in enough semesters to establish a criterion for dropping out.

The following variables are available: IDP, an identification code, unique to each student, which allows individual and at the same time anonymous monitoring; student's gender; student's date of birth; semester of the student's enrollment; codes of the subjects enrolled on by the student; final grades obtained in the subjects; number of credits that the subjects carry; and, finally, the academic programme, for example, Law or Computer Engineering. Specifically, there is a record for each subject enrolled on for the officially recognised degrees in Catalan from the start of the university until the end of the 2008/2009 academic year (in all 1,169,262 records). Note that enrollment at UOC is opened each semester (twice a year). A total of 19 degrees was offered during this period. Only valid enrollments were included, that is ones that have been formalised and paid for, thus excluding enrollments that were subsequently cancelled. A total enrollment history was provided for 84,230 students, although only 62,450 (those on the 16 programmes with enough available information) were analysed. This study ignores the pilot cohorts for programmes that began at the start of the university that limited student access during the first semester to a closed number and which, for administrative purposes, offered no access to new students during the second semester.

To analyse dropout, we only need to know whether a student is enrolled or not during a specific semester. Therefore, only the "IDP", "semester of enrollment", and "academic programme" fields were considered. The information from these fields was used to generate 17 files, 16 for each programme and a general file for all programmes, each of which contains a record for each student. These students are those who enrolled on one or more semesters for the programme during the period in question. The records generated have the following coding (as an example, a random record is selected):

$$
10104 ; 1 ; 1 ; 1 ; 0 ; 1 ; 0 ; 0 ; 0 ; 0 ; 0 ; 0 ; 0 ; 0 ; 0 ; 0 ; 0 ; 0 ; 0 ; 0 ; 0 ; 0
$$

Here, the first number is the IDP, followed by a binary string for the semester record ( " 1 " = student enrolled at least in one subject, " 0 " = student not enrolled in any subject). In this case, this student was enrolled during their three first semesters; they took a break for one semester, enrolled again for one semester and never enrolled again during the next 16 semesters. The specific nature of this string is that, for analysis purposes, all enrollment sequences have been put in the "same starting position", that is, the first semester when each IDP is enrolled on each degree is considered to be the same for all 
students on this degree. Obviously, the first element after IDP is always " 1 " (the first enrollment of each student). Finally, notice that the sequences "113000;1;0;0;0;0;0;0" and "10728;1;0;0" are different as more enrollment history about the first student is available for analysis (specifically, 7 semesters as opposed to 3). Our goal is precisely to determine the length of the trailing zeros that best captures dropout.

Once the enrollment sequences file for each programme is generated, the frequency of break sequences (i.e., of sequences of one or more zeroes) can then be analysed. This is performed through a pattern information analysis process that computes the longest break sequence (with " $1 ; 0 ; \ldots ; 0 ; 1$ " format) within each enrollment sequence for each individual, with the feature that if, for example, a student has taken a break once over five semesters and another one over two semesters, they will only be computed as having taken a break over five semesters (i.e., the longest one). Note that this process does not take graduates into consideration, as this could have led to them being considered as taking a break or abandoning their studies when they have in fact obtained their degree. Similarly, from a programme performance perspective, students are considered to have dropped out of a particular programme even if they move to another one.

Table 2

Analysis of the Break Sequences from Law (left) and Market Research \& Techniques Studies (right)

\begin{tabular}{|c|c|c|c|c|c|c|}
\hline & \multicolumn{4}{|l|}{ Law degree } & \multicolumn{4}{l|}{ MR\&T degree } \\
\hline $\mathrm{N}$ & NS & $\%$ & Accum. $\%$ & NS & $\%$ & Accum. \% \\
\hline 19 & 2 & 0.03 & 0.03 & --- & --- & --- \\
\hline 18 & 1 & 0.01 & 0.04 & --- & --- & --- \\
\hline 17 & 0 & 0 & 0.04 & --- & --- & --- \\
\hline 16 & 9 & 0.11 & 0.15 & --- & --- & --- \\
\hline 15 & 9 & 0.11 & 0.26 & --- & --- & --- \\
\hline 14 & 8 & 0.11 & 0.37 & --- & --- & --- \\
\hline 13 & 18 & 0.23 & 0.60 & --- & --- & --- \\
\hline 12 & 14 & 0.18 & 0.78 & --- & --- & --- \\
\hline 11 & 12 & 0.15 & 0.93 & --- & --- & --- \\
\hline 10 & 15 & 0.19 & 1.12 & --- & --- & --- \\
\hline 9 & 27 & 0.34 & 1.46 & --- & --- & --- \\
\hline 8 & 37 & 0.47 & 1.80 & 5 & 0.29 & 0.29 \\
\hline 7 & 29 & 0.37 & 2.27 & 3 & 0.17 & 0.46 \\
\hline 6 & 50 & 0.63 & 2.90 & 6 & 0.35 & 0.81 \\
\hline 5 & $\mathbf{6 9}$ & $\mathbf{0 . 8 7}$ & $\mathbf{3 . 7 7}$ & 7 & 0.41 & 1.22 \\
\hline 4 & 107 & 1.35 & 5.12 & 3 & 0.17 & 1.39 \\
\hline 3 & 173 & 2.18 & 7.30 & $\mathbf{3 0}$ & $\mathbf{1 . 7 5}$ & $\mathbf{3 . 1 4}$ \\
\hline 2 & 304 & 3.83 & 11.13 & 40 & 2.33 & 5.47 \\
\hline 1 & 815 & 10.27 & 21.40 & 141 & 8.21 & 13.68 \\
\hline 0 & 6239 & 78.60 & 100 & 1483 & 86.32 & 100 \\
\hline
\end{tabular}

Note. $\mathrm{N}$ is the number of consecutive semesters of break; NS is the number of students in such a situation. 
For exemplification purposes, Table 2 shows the probability of having a break of $\mathrm{N}$ semesters for the Law degree (with 7,938 students and a history of 24 semesters) and the Market Research and Techniques (MR\&T) degree (with 1,718 students and a history of 14 semesters). Columns in Table 2 are as follows: The first column gives the number of consecutive semesters of break (namely $\mathrm{N}$ ); the second column gives the number of students enrolled on the Law degree who take a break of length $\mathrm{N}$; the third and fourth columns give the percentage of such students with respect to the total number of students on the degree and the accumulated percentage, respectively. Columns 5-7 give the equivalent data for the MR\&T degree.

It can be seen that there are two students on the Law degree who take a break of 19 consecutive semesters, which may be surprising but shows the wide diversity of online students' enrollment behaviour. Nevertheless, in order to define dropout, we are interested in establishing a threshold for what we consider to be a reasonable period of break time. As shown in bold in Table 2, only 3.77\% of Law students take a break of five or more semesters. In the case of MR\&T students, a similar percentage (3.14\%) is found corresponding to three semesters or more, showing a relevant difference between academic programmes. In short, if we define dropout as taking a break of five or more semesters for the Law degree, we are assuming an error smaller than $5 \%$, which can be considered reasonable. However, dropout has to be defined for the MR\&T degree as having a break of only three semesters to give the same error assumption. Note that the fact that a Law student has the " $1 ; 0 ; 0 ; 0 ; 0 ; 0$ " string in their enrollment sequence is not sufficient information to see whether they will drop out, as we need an additional semester as mentioned above. This additional semester at the end of the sequence indicates whether the student has effectively dropped out $(1 ; 0 ; 0 ; 0 ; 0 ; 0 ; \mathbf{0})$ or not $(1 ; 0 ; 0 ; 0 ; 0 ; 0 ; 1)$. Following this criterion, we are able to label each student with a sequence of $\mathrm{N}$ or more zeroes as a dropout.

Therefore, a definition of the dropout rate for a specific programme would be reached empirically as being the proportion of students who have taken a break for $\mathrm{N}$ or more semesters out of the total number of students enrolled on the programme during the period in question. $\mathrm{N}$ is determined using the maximum probability of the $5 \%$ error rate in classifying the student as a dropout once they have taken a break of $\mathrm{N}$ or more semesters for that specific programme. As the choice of this threshold of allowed error directly determines the number of consecutive semesters that define dropout, it is interesting to look at the resulting number of semesters for thresholds of $1 \%$ and $10 \%$, as shown in Table 3. 
Table 3

Number of Consecutive Semesters that Define Dropout for 1\%, 5\%, and 10\% Error Threshold

\begin{tabular}{|l|c|c|c|}
\hline Programme & Threshold: $1 \%$ & Threshold: 5\% & Threshold: $10 \%$ \\
\hline Business Sci. & 11 & 5 & 3 \\
\hline Tech. Eng. in CM & 10 & 5 & 3 \\
\hline Tech. Eng. in CS & 11 & 5 & 3 \\
\hline Tourism & 6 & 3 & 2 \\
\hline Catalan Language & 10 & 4 & 2 \\
\hline Law & 11 & 5 & 3 \\
\hline Humanities & 10 & 5 & 3 \\
\hline Psychology & 7 & 3 & 2 \\
\hline Business Admin. & 9 & 4 & 2 \\
\hline Labour Sci. & 7 & 4 & 2 \\
\hline Political Sci. & 7 & 3 & 2 \\
\hline Audiovisual Comm. & 5 & 3 & 3 \\
\hline Documentation & 8 & 4 & 2 \\
\hline Market Res. \&Tec. & 6 & 3 & 3 \\
\hline Psycho-pedagogy & 12 & 4 & 3 \\
\hline Computer & 8 & 4 & 2 \\
Engineer. & & & 3 \\
\hline
\end{tabular}

As expected, the threshold value used has a major effect on the value of the number of semesters that define dropout; additionally, it would also affect the percentage of dropout for each course. It should be noted that a $1 \%$ threshold seems to be quite unrealistic, as would imply in many cases waiting for 10 consecutive break semesters or more before deciding that a student has dropped out, even worse than with the official definition. On the other hand, a 10\% assumed error seems to provide more uniform results, but we consider it to be excessive for our analysis purposes.

\section{Results}

On the basis of the work set out in the previous section, we establish a definition of dropout for each programme. Using an error threshold of $5 \%$, the specific programme in question is highly relevant. Although, logically, the definition of dropout in qualitative terms is the same for all courses, repeating the probability analysis carried out for all programmes gives different quantitative definitions depending on the values of the parameter of this definition, that is different $\mathrm{N}$ values for consecutive break semesters. 


\section{Differences between Programmes}

Table 4 provides a summary of the values associated with the 16 programmes analysed. For each programme, Table 4 shows the minimum number of consecutive break semesters needed to be considered a case of dropout is $\mathrm{N}$; the maximum error; the number of semesters ${ }^{2}$ defined in the curriculum of each programme, the number of semesters since the programme began and the number of students (NS) with at least $\mathrm{N}+1$ semesters used in the analysis. Finally, the last three columns make reference to the percentage of students obtaining the degree (accredited), the total dropout value, and finally the percentage of dropout after the $1^{\text {st }}$ semester.

Table 4

Summary of Results by Programme

\begin{tabular}{|l|l|l|c|c|r|l|l|l|}
\hline Programme & $\mathrm{N}$ & Error & $\begin{array}{l}\text { Length } \\
\text { (sems.) }\end{array}$ & $\begin{array}{l}\text { Data } \\
\text { (sems.) }\end{array}$ & NS & $\begin{array}{l}\text { Acc. } \\
\text { (\%) }\end{array}$ & $\begin{array}{l}\text { Total } \\
\text { dropout }\end{array}$ & $\begin{array}{l}\text { 1st sem. } \\
\text { dropout }\end{array}$ \\
\hline Business Sci. & 5 & $3.78 \%$ & 6 & 26 & 16,818 & $16.6 \%$ & $54.3 \%$ & $24.91 \%$ \\
\hline Tec. Eng. in CM & 5 & $4.11 \%$ & 6 & 22 & 5432 & $9.8 \%$ & $66.8 \%$ & $29.47 \%$ \\
\hline Tec. Eng. in CS & 5 & $4.46 \%$ & 6 & 22 & 7496 & $8.7 \%$ & $65.6 \%$ & $28.44 \%$ \\
\hline Tourism & 3 & $3.38 \%$ & 6 & 14 & 1889 & $9.6 \%$ & $49.7 \%$ & $26.10 \%$ \\
\hline Catalan & 4 & $3.89 \%$ & 8 & 22 & 1194 & $6.5 \%$ & $58.9 \%$ & $25.88 \%$ \\
\hline Law & 5 & $3.78 \%$ & 8 & 24 & 6149 & $10.2 \%$ & $54.0 \%$ & $26.72 \%$ \\
\hline Humanities & 5 & $3.75 \%$ & 8 & 24 & 5396 & $7.4 \%$ & $64.3 \%$ & $28.34 \%$ \\
\hline Psychology & 3 & $4.58 \%$ & 8 & 18 & 7674 & $3.8 \%$ & $56.5 \%$ & $28.81 \%$ \\
\hline Business Adm. & 4 & $3.75 \%$ & 4 & 22 & 3778 & $38.2 \%$ & $40.9 \%$ & $21.33 \%$ \\
\hline Labour Sci. & 4 & $2.82 \%$ & 4 & 16 & 3114 & $34.5 \%$ & $44.8 \%$ & $23.35 \%$ \\
\hline Political Sci. & 3 & $4.27 \%$ & 4 & 16 & 867 & $21.7 \%$ & $49.5 \%$ & $26.53 \%$ \\
\hline AV Comm. & 3 & $2.67 \%$ & 4 & 14 & 1070 & $21.9 \%$ & $43.7 \%$ & $21.12 \%$ \\
\hline Documentation & 4 & $4.48 \%$ & 4 & 20 & 2440 & $32.3 \%$ & $50.3 \%$ & $23.07 \%$ \\
\hline Market R. \& Tec. & 3 & $3.14 \%$ & 4 & 14 & 1374 & $32.4 \%$ & $38.0 \%$ & $18.05 \%$ \\
\hline Psychopedagogy & 4 & $4.86 \%$ & 4 & 26 & 4354 & $25.4 \%$ & $54.2 \%$ & $25.01 \%$ \\
\hline Comp. Eng. & 4 & $3.36 \%$ & 4 & 16 & 1541 & $30.1 \%$ & $37.3 \%$ & $15.96 \%$ \\
\hline TOTAL & 4 & $4.35 \%$ & --- & --- & 62,450 & $13.3 \%$ & $57.6 \%$ & $24.91 \%$ \\
\hline
\end{tabular}

As shown in Table 4, the number of semesters that define dropout in each programme has a particularly relevant variability. This figure varies between three and five semesters. Note that these figures are quite conservative, since using an upper bound of $10 \%$ would have reduced the number of consecutive break semesters, as can be seen in Table 3.

${ }^{2}$ Before the European Higher Education Area (EHEA) reorganization, programmes were divided in short ( $1^{\text {st }}$ cycle, three years), long $\left(1^{\text {st }}\right.$ and $2^{\text {nd }}$ cycle, five years $)$, and $2^{\text {nd }}$ cycle (two years). 
Initial analysis of these results shows that there appears to be no relationship between the type of programme content, that is technical or humanistic, and the number of semesters that determines dropout. For example, in the case of Computer Engineering, the value is high ( 5 semesters), but it is the same as in the case of Humanities. On the other hand, it does seem that in programmes where students have prior higher education experience related to the curriculum they are studying (in Spain known as "second cycle" degrees ${ }^{3}$ ), dropout is decided with fewer semesters than on programmes where this experience is not required (known as "first cycle" or "first and second cycle"). Specifically, it can be seen that, for first-cycle or first-and-second-cycle programmes, up to five degrees have an $\mathrm{N}=5$ semesters value, Catalan language has a value of $\mathrm{N}=4$ and Psychology has a value of $\mathrm{N}=3$. For second-cycle programmes, there is no degree with an $\mathrm{N}=5$ semesters value, and the majority of programmes have a value of $\mathrm{N}=4$. From a different perspective that would in some way confirm our results; recent research at the UOC (Carnoy et al., 2011) shows that students taking shorter degree courses at UOC are much more likely to complete their degrees.

\section{Total Dropout and First Semester Dropout}

As stated previously, official criteria for quantifying dropout are not applicable in order to have a perception of the whole dropout problem. As an example, the cohorts of two representative programmes have been compared according to both dropout definitions. According to the official definition of dropout, we need to wait until the $8^{\text {th }}$ or $10^{\text {th }}$ (Business Science and Humanities, respectively) semester in order to measure it. On the other hand, following the definition proposed in this paper, the dropout is detected when it really happens, mainly at the first semesters.

With such definition, the percentage of dropout students can be computed for each programme. Concerning total dropout, it can be seen ${ }^{4}$ that for the group of first-cycle and first-second-cycle programmes, Tourism and Computer Engineering seem to have a lower/higher dropout level than the rest of the degrees of this group, respectively. For the group of second-cycle programmes, differences are weaker and only the programme of Psychopedagogy would seem to have significantly higher dropout proportion values than the rest of the programmes in the group.

It is important to notice that dropout in the first semesters seems to follow a similar pattern across all programmes, as the probability of dropping out is very high the second semester, then rapidly decreases until it reaches a relative plateau in approximately the sixth semester (Grau-Valldosera \& Minguillón, 2013), as shown in Figure 1. The proportion of first semester dropouts over total dropout follows a quite regular pattern (with values concentrated in an interval between $43 \%$ and $52 \%$ ), which

\footnotetext{
${ }^{3}$ It should be borne in mind that the data for this study belongs to programmes with a structure before the existence of the European Higher Education Area (also known as the Bologna Process).

${ }^{4}$ For more details on the statistical analysis process applied see Marascuilo (1966) and Natrella (1963).
} 
would confirm the importance of first semester dropout (Roberts, 1984; Tyler-Smith, 2006). This similar behaviour shows that some reasons for dropping out are out of the scope of a single programme, and that there must be reasons related to the institution and/or the inherent characteristics of the learner (level of motivation, e-learning readiness, etc.).

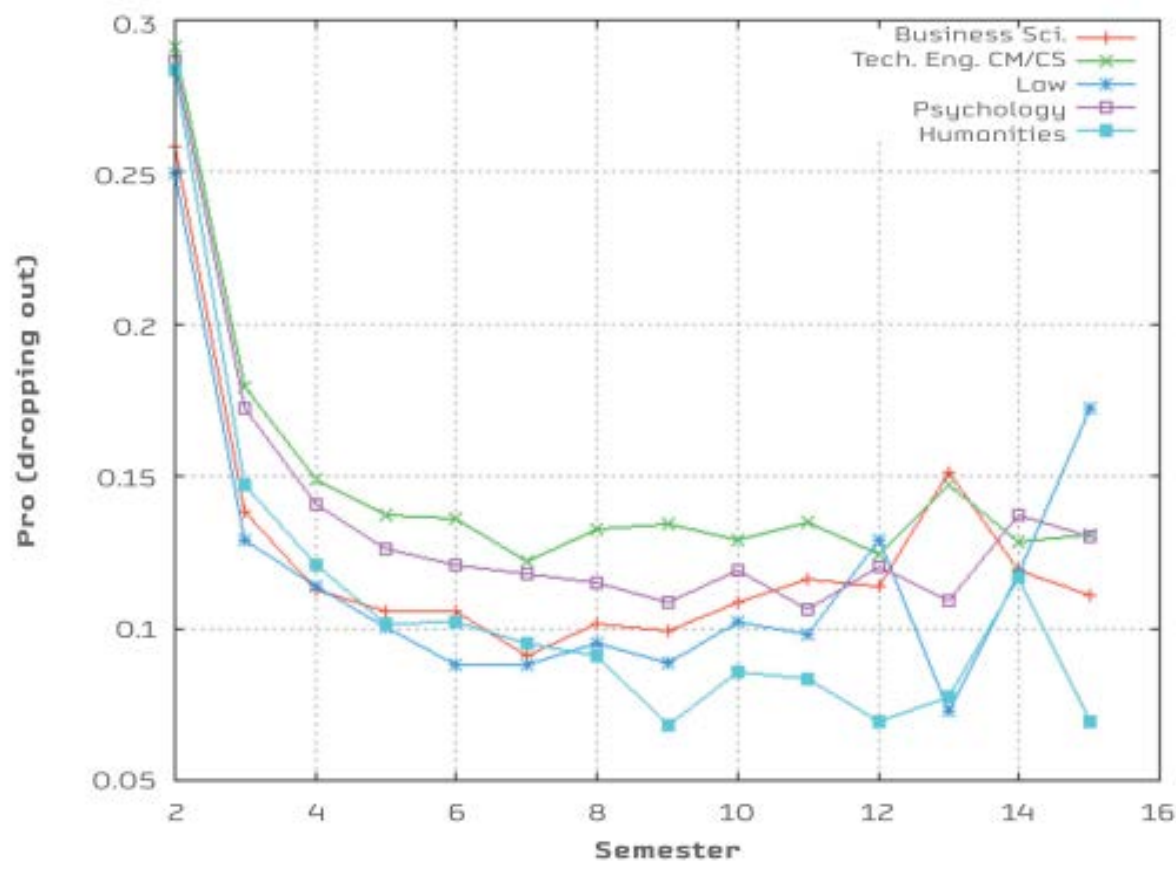

Figure 1. Probability of dropping out before starting a new semester.

\section{Conclusions}

This paper deals with the formulation of a definition of dropout that is suitable to online/distance higher education institutions with relaxed enrollment requirements, such as the Universitat Oberta de Catalunya. It should be noted that the dropout official definition in Spain does not reflect the nature of online higher education. The goal of reaching a definition can be seen as key by bearing in mind that most UOC students are adults with work and family commitments as well as those linked to continuing education and, therefore, have a greater tendency to take academic breaks. However, this is not an easy goal to achieve, due to the fact that these break periods could be interpreted as either exactly that (i.e., periods of rest) or, at some point, as indicators of having definitively dropped out of their studies. Nevertheless, the term 'definitively' cannot be taken literally since in most cases students are allowed to restart their studies if they want to.

Given the difficulty in describing dropout at the UOC and other institutions that offer distance higher education with no (or low) permanence requirements, we have focused 
on finding a suitable parameterized definition for dropout, taking into account programme characteristics. This definition, based on empirical data and very close to students' enrollment behaviour, overcomes the different "time limit to graduation" institutional regulations of distance higher education institutions, permitting some generalization. Other aspects like the degree of openness and the flexibility of enrollment dates, which are particular to each institution, can be also considered.

The proposed definition uses the minimum number of consecutive semesters of nonenrollment (i.e., $\mathrm{N}$ ) that enables us to classify a student as a dropout for a specific programme. We should stress, however, that this $\mathrm{N}$ is different for each programme, and that herein lays the potential for the definition of dropout reached in this paper. As conjectured, a "one-size-fits-all" definition for dropout cannot be established at university level in order to really understand the dropout problem. None of the definitions for either brick-and-mortar or distance universities include a unique definition of dropout that takes account of the probability of restarting courses after one or more break periods (so a student would not be considered a dropout case). Furthermore, our definition allows us to detect dropouts before the official definition establishes a student is a dropout.

The definition is highly sensitive to the characteristics of each programme. In programmes where prior higher education experience is required, the decision to drop out is made more quickly (on average, almost one semester before) than in programmes where such a condition is not needed. This may be due to students having clearer objectives in these types of programmes, which are based on completed studies (a previous degree). It is also related to the shorter theoretical duration of such degrees. With the dropout definition in hand, significant differences can be exposed between programmes of similar duration with respect to the total (or final) dropout values.

Another output of the analysis is the detection of high dropout indexes in the first semesters, which could be caused probably by "the clash between the student (becoming a student again for adult learners with different expectations and personal situation) and the institution (methodology, support, etc.)" (Grau-Valldosera \& Minguillón, 2013). Early dropout detection will help institutions to take corrective measures without waiting for the official definition to be applicable. It is important to remark that a more finely tuned analysis of dropout students should help educational institutions allocate their increasingly scarce resources in their fight against dropout. In fact, some institutional actions can be taken during the very first semester, as an important percentage of dropouts occur in such a period, for instance, reinforcing mentoring strategies and promoting closer relationships between the student and the institution by means of a personalized channel (i.e., a mentor), rather than expecting the student to use the traditional channels for obtaining institutional support.

Additionally, it should be noted that the main analysis conducted in this paper, which allows us to establish whether a student can be considered a dropout or not, is the starting point towards undertaking a close study of the characteristics of students who 
drop out. Such a study will be based on data already collected, such as the age and gender of students as well as other variables related to the number and kind of subjects taken every semester. The addition of new variables not collected yet should be considered also, as the result of a qualitative analysis extending the one undertaken in this paper and also from a review of previous research on this matter. Examples of variables that could be related to dropout are motivation (Hartnett et al., 2011; Paas et al., 2005), previous education (Poellhuber et al., 2008), e-learning readiness (DupinBryant, 2004), and perception of connectedness (Bolliger \& Inan, 2012). Such variables might also reveal potential areas of improvement. For instance, if e-learning readiness is a barrier, future students could be attracted and retained by offering them free preliminary courses about becoming an online learner.

Given that dropout is a complex, multifaceted problem, the option of adopting a design based research methodology seems to be the most plausible. This would imply following an iterative process (Shavelson et al., 2003), and considering at all moments the solutions to this problem as unfinished implementations (Stewart \& Williams, 2005). Higher education institutions need to be continuously analyzing dropout semester after semester, in order to build reasonable models. Once the characteristics of dropout students and the causes of dropout have been determined, establishing corrective actions (Woodley, 2004; Tyler-Smith, 2006) that have a positive effect on reducing dropout should report benefits both at institutional and personal levels, especially for those students who have given up the fight with a sense of not having achieved their learning objectives, and, more dramatically, for those dropping out after their first semester. Future research based on the dropout definition built in this paper will include the creation of mathematical models for predicting dropout at a given semester and identifying the underlying causes, which might be different. More concretely, we are interested in establishing a threshold for differentiating between early dropout and midterm dropout, which is probably closer to the concept of attrition and caused by different reasons.

\section{Acknowledgements}

This paper has been partially supported by the Spanish Government project MAVSEL TIN2010-21715-C02. 


\section{References}

Astin, A. (1971). Predicting academic performance in college: Selectivity data for 2300 American colleges. New York: Free Press.

Bolliger, D. U., \& Inan, F. A.(2012). Development and validation of the Online Student Connectedness Survey (OSCS). The International Review of Research in Open and Distance Learning, 13(3), 41-65. Retrieved from http:// www.irrodl.org/index.php/irrodl/article/view/ 1171

Carnoy, M., Rabling, B., Castaño-Munoz, J ., Duart Montoliu, J ., \& Sancho-Vinuesa, T. (2011). Who attends and completes virtual universities: The case of the Open University of Catalonia (UOC). Higher Education, 63(1), 53-82.

Castles, J . (2004). Persistence and the adult learner: Factors affecting persistence in Open University students. Active Learning in Higher Education, 5(2), 166- 179.

Cheung, L. L. W., \& Kan, A. C. N. (2002). Evaluation of factors related to student performance in a distance-learning business communication course. J ournal of Education for Business, 77(5), 257.

Conferencia de Rectores de las Universidades Españolas (CRUE). (2008). Universidad Española en Cifras. Madrid. Retrieved from http:// www.crue.org/ export/sites/Crue/Publicaciones/Documentos/UEC/ UEC 2008.pdf

Dupin-Bryant, P. (2004). Pre-entry variables related to retention in online distance education. American J ournal of Distance Education, 18(4), 199- 206.

Finnegan, C., Morris, L., \& Lee, K. (2009). Differences by course discipline on student behavior, persistence, and achievement in online courses of undergraduate general education. J ournal of College Student Retention: Research, Theory and Practice, 10(1), 39-54.

Grau-Valldosera, J ., \& Minguillón, J . (2013). When procrastination leads to dropping out: Analysing students at risk. eLC Research Paper Series, 6, 63-74. Retrieved from http:// www.uoc.edu/ ojs/index.php/ elcrps/ article/ view/ 1872

Frydenberg, J . (2007). Persistence in university continuing education online classes. The International Review of Research in Open and Distance Learning, 8(3), 115. Retrieved from http:// www.irrodl.org/ index.php/irrodl/ article/ view/ 375/934

Hartnett, M., St. George, A., \& Dron, J . (2011). Examining motivation in online distance learning environments: Complex, multifaceted and situation-dependent. The International Review Of Research In Open And Distance Learning, 12(6), 20- 


\section{Retrieved from}

\section{http:// www.irrodl.org/ index.php/irrodl/ article/ view/ 1030/ 1954}

Ivankova, N. V., \& Stick, S. L. (2007). Students' persistence in a distributed doctoral program in educational leadership in higher education: A mixed methods study. Research in Higher Education, 48(1), 93- 135.

J ohnes, J . (1990). Determinants of student wastage in higher education. Studies in Higher Education, 15(1), 87.

Kemp, V. (2002). Persistence of adult learners in distance education. American J ournal of Distance Education, 16(2), 65.

Lee, Y., \& Choi, J . (2011). A review of online course dropout research: implications for practice and future research. Educational Technology Research and Development, 59(5), 593-618.

Levy, Y. (2007). Comparing dropouts and persistence in e-learning courses. Computers \&Education, 48(2), 185-204.

Moore, K., Bartkovich, J ., Fetzner, M., \& Ison, S. (2003). Success in cyberspace: Student retention in online courses. J ournal of Applied Research in the Community College, 10(2), 12.

Morgan, C. K., \&Tam, M. (1999). Unravelling the complexities of distance education student attrition. Distance Education, 20(1), 96- 108.

Morris, L. V., Finnegan, C., \&Wu, S. (2005). Tracking student behavior, persistence, and achievement in online courses. The Internet and Higher Education, 8(3), 221- 231.

Natrella, M. (1963). e-Handbook of statistical methods. Retrieved from http:// www.itl.nist.gov/ div898/handbook/ prc/ section4/prc474.htm

OECD (2012). "How many young people graduate from tertiary education?" In Education at a glance 2012: Highlights. OECD Publishing. Retrieved from http:// dx.doi.org/ 10.1787/ eag_highlights-2012-7-en

Paas, F., Tuovinen, J ., van Merrienböer, J ., \& Aubteen Darabi, A. (2005). A motivational perspective on the relation between mental effort and performance: Optimizing learner involvement in instruction. Educational Technology Research and Development, 53(3), 25-34.

Perry, B., Boman, J ., Care, W. D., Edwards, M., \& Park, C. (2008). Why do students withdraw from online graduate nursing and health studies education? J ournal of Educators Online, 5(1), 1- 17. 
Pierrakeas, C., Xenos, M., Panagiotakopoulos, C., \&Vergidis, D. (2004). A comparative study of dropout rates and causes for two different distance education courses. International Review of Research in Open and Distance Learning, 5(2), 1- 13. Retrieved from http:/ / www.irrodl.org/index.php/irrodl/ article/view/ 183

Pigliapoco, E., \& Bogliolo, A. (2008). The effects of psychological sense of community in online and face-to-face academic courses. International J ournal of Emerging Technologies in Learning, 3(4), 60-69.

Poellhuber, B., Chomienne, M., \& Karsenti, T. (2008). The effect of peer collaboration and collaborative learning on self-efficacy and persistence in a learner-paced continuous intake model. J ournal of Distance Education, 22(3), 41-62.

Roberts, D. (1984). Ways and means of reducing early student drop-out rates. Distance Education, 5(1), 50-71.

Sangrà, A. (2002). A newlearning model for the information and knowledge society: The case of the Universitat Oberta de Catalunya (UOC), Spain. The International Review of Research in Open and Distance Learning, 2(2). Retrieved from http:// www.irrodl.org/index.php/irrodl/article/view/ 55/ 114

Shavelson, R. J ., Phillips, D C., Towne, L., \&Feuer, M. (2003). On the science of education design studies. Educational Researcher, 32(1), 25.

Shin, N., \& Kim, J . (1999). An exploration of learner progress and drop-out in Korea National Open University. Distance Education, 20(1), 81- 95.

Tello, S. (2007). An analysis of student persistence in online education. International J ournal of Information and Communication Technology Education, 3(3), 4762 .

Tinto, V. (1982). Defining dropout: A matter of perspective. New Directions for Institutional Research, 1982(36), 3-15.

Tinto, V. (1975). Dropout from higher education: A theoretical synthesis of recent research. Review of Educational Research, 45(1), 89-125.

Tyler-Smith, K. (2006). Early attrition among first time eLearners: A review of factors that contribute to drop-out, withdrawal and non-completion rates of adult learners undertaking eLearning programmes. J ournal of Online Learning and Teaching. Retrieved from http://jolt.merlot.org/vol2no2/ tyler-smith.htm

Willging, P. A., \& Johnson, S. D. (2004). Factors that influence students' decision to dropout of online courses. J ournal of Asynchronous Learning Networks, 8(4), 105- 118. 
Williams, R. S., Stewart, J ., \& Slack, R. (2005). Social learning and technological innovation: Experimenting with ICTs. Edward Elgar: Aldershot.

Woodley, A. (2004). Conceptualizing student dropout in part-time distance education: Pathologising the normal? Open Learning, 19(1), 47-63.

\section{Athabasca University $\mathbf{1}$}

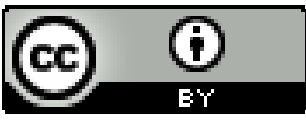

